\title{
A clave do poético
}

Yudith Rosenbaum

CC R ENEDITo Nunes é um tesouro na3 cional guardado na Amazônia há décadas", diz Leyla Perrone-Moisés no prefácio ao volume $A$ clave do poético, que reúne ensaios já consagrados e outros inéditos do crítico paraense, ao longo de mais de quarenta anos de produção.

Essa riqueza toda, síntese de uma assombrosa erudição e de um luminoso pensamento - que aproximou a crítica literária brasileira de suas raízes filosóficas -, habita "o menos provinciano dos intelectuais", como prossegue PerroneMoisés.

A despeito de sua morada distante dos centros culturais hegemônicos, Benedito Nunes é um pensador atento, entre outros aspectos, às inserções de obras e autores nacionais e estrangeiros aos grandes contextos histórico-culturais a que devem sua emergência.

Essa marca cosmopolita do autor de obras referenciais, como Introdução à filosofia da arte (1967) e Passagem para o poético: filosofia e poesia em Heidegger (1986), ressalta, do início ao fim, para o leitor desses ensaios. Nenhum escritor, nenhum texto se apresenta isolado da linhagem maior a que pertence, da geração de seus antecessores e do tempo que o engendrou. $\mathrm{O}$ autorretrato do crítico, no ensaio de abertura "Meu caminho na crítica", explicita esse traço: "o meu interesse intelectual não nasce nem acaba no campo da crítica literária. Amplificado à compreensão das obras de arte, incluindo as literárias, é também coextensivo, em conjunto, à interpretação da cultura e à explicação da Natureza”. E conclui: “Um interesse tão reflexivo quanto abrangente, é, portanto, mais filosófico do que apenas literário" (p.23).

Seu interesse pelas "filosofias de viés literário", como ele denomina - Heidegger, Sartre e Merleau-Ponty -, bem como pelos românticos alemães que uniram poesia à filosofia, constitui a base de um olhar crítico que soube dinamizar contrários aparentes como imagem e ideia, percepção e conceito. Munido, portanto, da consciência de que "não há crítica literária sem perspectiva filosófica", Benedito Nunes se debruça sobre as obras com a paixão dos amantes e a precisão detalhista dos exegetas.

Assim instrumentalizado - o que nada seria sem a aguda intuição de alguém vocacionado para apreender os sentidos essenciais -, Nunes parece inclinar-se, na transversalidade desses ensaios tão diversos, para as grandes temáticas metafísicas: a Morte, o Tempo, a História, a Não História e, sobretudo, o Mito e a Mística. Mas aqui vale o alerta da prefaciadora: "como filósofo contemporâneo da crise da metafísica, leitor de Nietzsche, Heidegger e Wittgenstein, ele não busca, na literatura, a Verdade, mas verdades no plural, ou melhor, diferentes maneiras de dizer e compensar a perda da Verdade" (p.18). De todo modo, o que surpreende na escrita e na reflexão de Nunes é a sua perspectiva unificadora e totalizante das múltiplas faces de um real sempre avesso ao deciframento. Movido por um desejo de saber, provindo de sua vertente filosófica, e de um desejo de dizer, que é sua contraface poética, o ensaísta octogenário não recua ante a opacidade das palavras. Aceitando o limite do indizível, converte 
o ensaio em experiência existencial, em que sujeito e objeto se transformam mutuamente.

Sua indagação de fundo não é modesta: "De que verdades essenciais pode falar a literatura?" (p.41). E para perseguir tais verdades o crítico respeita um lema de raiz wittgensteiniana: "Quando a filosofia e a ciência se calam, é sempre o poema que diz a última palavra".

O organizador de A clave do poético, Victor Sales Pinheiro, dividiu o extenso material em duas partes. $\mathrm{Na}$ primeira, "Pensando a literatura", reúnem-se os percursos mais teóricos sobre a crítica literária brasileira e estrangeira, abrangendo a teoria e a história literárias. A segunda, "Crítica de autores", abre um amplo leque de análises de escritores nacionais (a maior parte), com ensaios canônicos sobre Clarice Lispector e Carlos Drummond de Andrade, além de estudos sobre autores contemporâneos (Raduan Nassar e Milton Hatoum), outros sobre conterrâneos de Nunes, como os paraenses Dalcídio Jurandir e Max Martins, e ainda belas interpretações de T. S. Eliot e Rilke. Encontram-se até mesmo reveladores comentários sobre a tradução da poesia erótica de Safo por Joaquim Brasil Fontes, colocando em fértil cotejo a lírica grega com a subjetividade lírica dos modernos.

Pela lista citada, pode-se perceber a variedade de temas e obras abordados, todos visitados com a mesma contundência e igual didatismo, oferecendo generosamente ao leitor um grande panorama da literatura mundial com a qual cada texto dialoga, bem como as fontes filosóficas que o alimentam. Assim é que, em um dos ensaios mais extensos do livro - "Crítica literária no Brasil, ontem e hoje" -, o autor realiza uma retrospectiva das correntes críticas brasileiras do fim do século
XIX, partindo da geração republicana e antiescravagista de 1870 (Silvio Romero e José Veríssimo), passando pela "pletora" dos anos 1940/1950, com Álvaro Lins, Sergio Milliet e Antonio Candido, até os poetas críticos Mário Faustino (ao qual também dedica um ensaio afetuoso na segunda parte, "A poesia de meu amigo Mário"), Décio Pignatari, Augusto de Campos, Haroldo de Campos, Ferreira Gullar e Mário Chamie, desaguando nos anos 1980 e 1990 com seus ilustres professores uspianos, alguns lembrados com atenção por Nunes (Davi Arrigucci Jr. e João Adolfo Hansen, entre outros).

Ao final desse percurso, ao qual nada escapa que seja estruturante para o pensamento crítico literário atual (veja-se o exemplo de Afrânio Coutinho e sua crítica como ciência e método, marcando a história da Nova Crítica e de seu "close reading” no Brasil), o ensaísta é contundente ao diagnosticar a crise da crítica - a falência de sua capacidade julgadora e a própria extinção dos suplementos literários -, ao lado de uma crise da própria literatura: "talvez seja mesmo a crise da crítica o efeito exterior de uma crise da própria literatura, combalida, intoxicada, inconformada, maquilada dentro do vigente sistema de valores midiáticos da vida cultural brasileira globalizada" (p.66). Seu arremate, porém, mostra a positividade exemplar de sua atitude crítica: "No entanto, crise não é catástrofe. Crise é incerteza acerca do que fazer agora e do que virá depois" (p.66).

Cabem, ainda, na primeira parte, resenhas ensaísticas sobre alguns livros que marcaram a história da crítica, como o elogio de Nunes ao texto "A interpretação da obra literária”, de Alfredo Bosi, que finaliza o livro Céu, inferno. Uma vez dentro do campo da hermenêutica, o 
crítico não hesita em historicizar a prática da exegese desde o período helênico (referindo-se à palavra mágico-religiosa dos oráculos), atravessando as leituras teológicas, até o seu ressurgimento no romantismo, com Schleiermacher e a orientação historicista de Dilthey. O ensaio de Bosi, visto sob essa perspectiva, amplia-se e se adensa para fazer reverberar a pergunta comum em ambos: para que interpretar? Alfredo Bosi será novamente o interlocutor escolhido no ensaio "A invenção machadiana", no qual se investigam as matrizes do olhar machadiano no pensamento do Oitocentos, segundo Oenigma do olhar, resenhado por Nunes em 1999.

Outros estudiosos ganham a mesma desdobrada atenção. É o caso do prefácio à primeira edição, em 1979, de Mimesis e modernidade: formas das sombras, de Luis Costa Lima. Para elucidar que o método de Lima não se detém no conhecimento da estrutura, mas persegue o nexo entre "a ordem das estruturas e a ordem dos acontecimentos", Nunes põe em jogo os grandes filósofos da representação, de Aristóteles a Kant. Sua visada coloca Lima na tradição humanística "que preservou a equivalência entre mimesis e poiesis", para concluir com um fecho que também revela a sua posição como crítico: "Sob tal perspectiva filosófica, marcadamente epistemológica, a crítica literária, tornando-se uma crítica da razão estética, pode estabelecer a conexão interdisciplinar das ciências humanas e dos estudos humanísticos, sem a qual o cultivo da literatura se estiola no culto reverencial das belas-letras e no diletantismo do espírito" (p.137, grifo do autor).

Em "Reflexões sobre o moderno romance brasileiro" e "A recente poesia brasileira: expressão e forma", os leitores ganham uma aula magna sobre os prin- cipais autores da modernidade brasileira. Mesmo com o olhar focado no presente dos anos 1980, Nunes insiste na mirada retrospectiva e faz remontar cada obra comentada às suas matrizes históricas: verso livre, coloquialismo, humor e outras conquistas modernistas. Nesses dois ensaios de viva acuidade crítica para textos contemporâneos ao autor - o primeiro é de 1982 e o segundo, de 1999 -, Nunes cunha expressões lapidares, como "o sertanismo da palavra" para a poesia de Manoel de Barros, e frases esclarecedoras, como quando se refere ao grotesco e ao obsceno do decênio de 1970 na prosa: "O obsceno não é mais o irreverente desvestimento das coberturas sociais do corpo humano, visto de baixo para cima, genital e sexualmente, e da livre fornicatio que Macunaíma e Serafim executam com muita graça, e sim o exercício da violência e do desespero, onde se espelha, como em $O$ caso Morel (1973), de Rubem Fonseca, a imagem do homem dividido, à procura de sua identidade" (p.155.

Encerrando a primeira parte, deparamos com a curiosa entrevista que Nunes deu a ninguém menos que Clarice Lispector. As perguntas versaram sobre os rumos da literatura brasileira na época (anos 1970), remetendo às relações entre modernismo e cultura brasileira. Em meio a profundas reflexões sobre a "literaridade" que marca a autonomia do literário a partir da modernidade, Nunes reafirma aquilo que é o crivo de sua personalidade crítica: "A literatura pertence cada vez mais ao domínio do pensamento. Há um poiesis comum que se reparte entre ela e a filosofia" (p.191). Vale a pena, também, citar aqui o modo como Lispector apresenta seu entrevistado, referindo-se ao livro de Nunes Leitura de Clarice Lispec- 
tor, de 1973, o que revela um pouco da essência de ambos: "Fiquei surpreendida quando ele me disse que sofreu muito ao escrever sobre mim. Minha opinião é que ele sofreu porque é mais artista que crítico: ele me viveu e se viveu nesse livro. $\mathrm{O}$ livro não me elogia, só interpreta profundamente" (p.186).

Vale a pena relembrar, ainda a respeito de Clarice Lispector, o modo inaugural como Nunes plantou o terreno crítico filosófico sobre a autora. Desde então não se tem um único ensaio acadêmico, tendo Lispector como objeto de estudo, que não passe pelas análises fundantes que $o$ ensaísta realizou sobre a autora de $A$ hora da estrela. Dois textos dedicados a ela, "A paixão de Lispector" e "A escrita da paixão" (esse segundo mais centrado em A paixão segundo G.H.), fazem um enorme apanhado de toda a obra de Clarice e revelam muitas das principais linhas de força de sua literatura. $\mathrm{O}$ jogo da linguagem nos textos claricianos se descortina como paradoxo (figura privilegiada de sua obra), paragem contemplativa, fruição visual e uma simbólica do enigma. A análise heideggeriana expõe o âmago de uma autora que se busca e se perde na insuficiência das palavras. Encantado pela escrita da paixão de Clarice, Nunes sintetiza a pergunta que move o último romance da autora editado em vida, $A$ hora da estrela:

Penso, logo existo. Mas eu que penso, indagava Descartes, quem sou? Parodiando-se essa passagem do texto cartesiano, podemos atribuir a Clarice Lispector, diante do jogo de linguagem transformado num jogo de identidade, a invenção de um cogito da narrativa narro, logo sou - e perguntar por ela: Mas en que narro, quem sou? (p.214, grifo do autor)
Se tomarmos os ensaios de Nunes dedicados a Drummond, perceberemos a potência reflexiva do ensaísta ao fazer reverberar vozes tão díspares na sua poesia mineira e universal. Em "Drummond: poeta anglo-francês", o crítico discute as traduções para o inglês que o poeta norteamericano Robert Stock (o "Bob" ou "O homem da Matinha", como era conhecido durante os cinco anos em que morou em Belém e iniciou os jovens colegas paraenses na literatura de língua inglesa) fez dos poemas "Oficina irritada", "A Máquina do Mundo" e "José", entre outros. No mesmo ensaio, Nunes comenta traduções de Jean-Michel Massa de outras poesias de Drummond para o francês, comparando as soluções encontradas pelos dois tradutores. Já em "Carlos Drummond: a morte absoluta", o trabalho do crítico é simultaneamente minucioso e grandioso. Nunes acompanha a temática da morte desde o livro Brejo das almas até Boitempo, mostrando a recorrência da ideia de "evasão thanática". Esse topos assumiria em Drummond do Sentimento do mundo "uma repulsa irônica a princípio, obstinada em seguida, e que depois se transforma numa atitude de resistência ética" (p.242) em meio às sombras da Segunda Guerra Mundial, segundo a lente analítica de Nunes. E mais adiante completa: "a experiência de morte, na poesia de Carlos Drummond, a partir de $A$ rosa do povo, assimilará reflexivamente, através da experiência decepcionante do tempo e do amor, o próprio desejo de aniquilamento" (p.243).

Em novo giro analítico, no mesmo ensaio, Nunes mostra o "poeta do infinito e da matéria" em sua aprendizagem montaigniana, fazendo do humor uma arma de despojamento e humildade. Aproximando Drummond dos paradoxos e do 


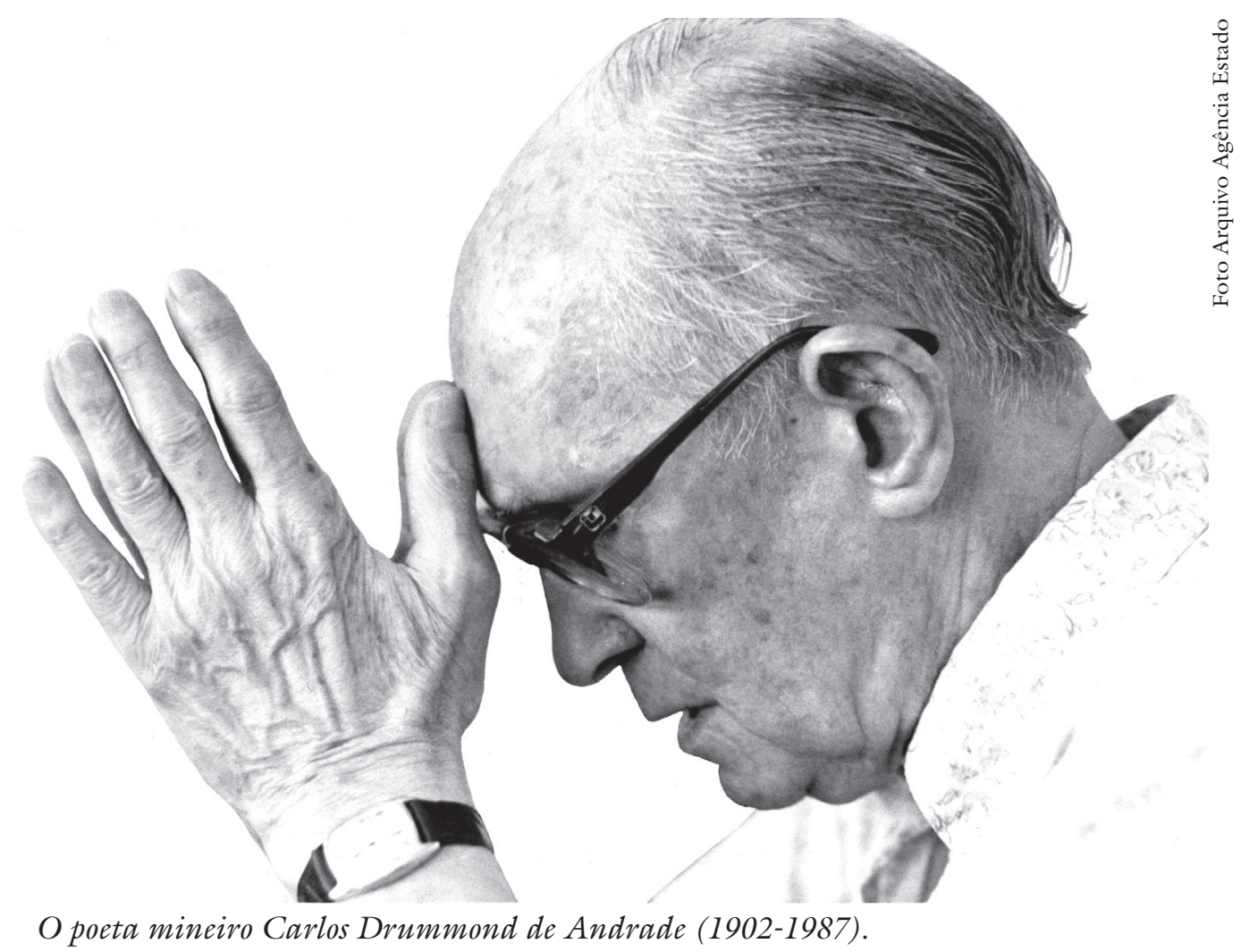

ceticismo de Tristan-Corbière, bem como do humor (mas não tão melancólico) de Jules Laforgue, Nunes estabelece contatos inusitados entre os poetas, trazendo à tona intersecções antes silenciosas. Em mais uma de suas formulações lapidares, lemos:

Nem pessimista nem místico, Carlos Drummond não pertence à estirpe dos poetas que desprezam a vida e tampouco se enfileira na dos predicadores da morte. Seu lirismo de penetração tende a depurar tanto a afirmação da vida quanto o impulso de evasão contra o qual se insurgiu num esforço de resistência ética. (p.247)

Assim mapeado, Drummond ganha toda a sua complexidade na dinâmica polar entre o desejo de fuga e a afirmação da vida.

Para que não se pense que Nunes transita apenas pela literatura da modernida- de, leia-se o curto ensaio "Os tristes, brutos índios de Vieira, ou um missionário aturdido", sobre o "Sermão da epifania", escrito por Vieira em 1662. A questão do poder civilizatório da religião (e os índios a ela não acederiam pela falta de discurso, segundo Vieira) será discutida nesse e no ensaio "A cidade sagrada", sobre a fundação de Belo Monte, em Canudos, liderada por Antonio Conselheiro. Nesse caso, é o livro de Walnice Galvão, O império de Belo Monte: vida e morte de Canudos, que motiva a densa análise das questões messiânicas, políticas e religiosas, combinadas no meio do sertão.

$\mathrm{Na}$ seção "Brasileiros contemporâneos", enfeixam-se ensaios instigantes, que dão à clave ensaística do autor um colorido singular. "A volta do mito na ficção brasileira" é um desses textos inspiradores de outros, que dele certamente decorrerão. Trata-se de um estudo das ra- 


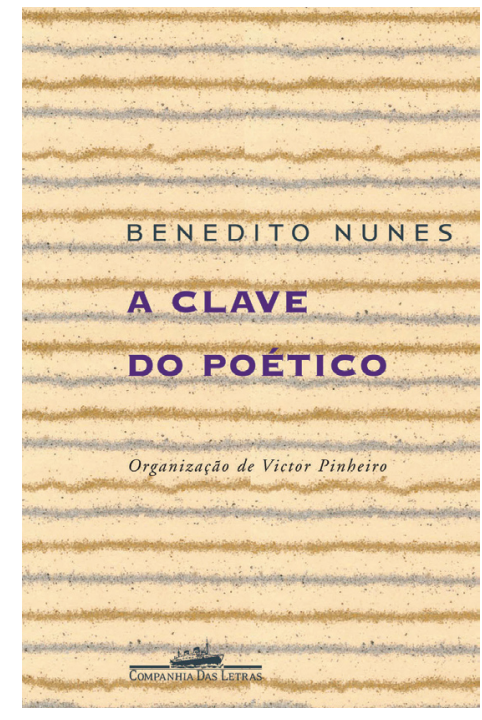

NUNES, B. A clave do poético.

Org. Victor Sales Pinheiro.

São Paulo: Cia. das Letras, 2009. 440p.

ízes míticas da literatura brasileira no romantismo e no modernismo brasileiros, para depois analisar seu ressurgimento, no que seria o terceiro surto do mito, em três romances contemporâneos: $A$ pedra do reino (1971), de Ariano Suassuna; Lavoura arcaica (1975), de Raduan Nassar; e Dois irmãos (2000), de Milton Hatoum. No primeiro, desvelam-se as histórias de cordel nordestinas; no segundo, é a inversão da parábola bíblica da volta do filho pródigo; e no último, o encontro tríplice da etnografia, da religião e da literatura, com a saga veterotestamentária dos filhos de Isaac, Esaú e Jacó. O retorno do mito nessas narrativas se dá de modo tal que leva a mais uma definição sintética do autor: trata-se de romances mitomórficos. Nunes explica:

Nenhum deles gera mitos novos como os anteriores [Grande sertão: Veredas, de Guimarães Rosa e A Paixão Segundo G.H., de Clarice Lispector]; todos vão buscar no repertório bíblico e po- pular figuras míticas já existentes, por eles reformuladas e postas a funcionar como modelos arquetípicos das histórias contadas. Esses romances não são, por isso, mitogênicos, mas pela função modelar, ordenadora, que emprestam a tais figuras na condução da história e na expectativa do leitor são mitomórficos. (p.295)

O trabalho hermenêutico de Nunes expõe, ainda, seus bastidores na análise filosófica de um poema de Haroldo de Campos, "Austineia desvairada" (no ensaio "Encontro em Austin"). Aqui o poema de Campos é lido à luz do pensamento de Heidegger e decifrado em sua neblina semântica e sintática. Cabe ressaltar como Nunes transita entre posições críticas tão distintas - como as de Haroldo de Campos e Alfredo Bosi -, colocando em primeiro plano não as possíveis dissidências, mas o alcance crítico de cada pensador. Essa atitude, isenta e estrita, rende reflexões ricas e oportunas.

Nem sempre é fácil ler os ensaios desse volume. A matéria filosófica de que trata e o estilo denso, muitas vezes tortuoso (pelo excesso de frases colocadas como aposto), pedem esforço dobrado do leitor interessado. Mas o espectro de temas, ideias e insights que fazem a trama dessa reunião de textos constrói um repertório duradouro e operante para os que exercem a crítica sem preconceitos teóricos e sem temor da busca pela significação.

Yudith Rosenbaum é professora de Literatura Brasileira na USP e autora dos livros Manuel Bandeira: uma poesia da ausência (Edusp/Imago, 1993) e Metamorfoses do mal: uma leitura de Clarice Lispector (Edusp/Fapesp, 1999), entre outros. @ - yudith@uol.com.br 